\title{
Car restraints and seating position for prevention of motor vehicle injuries in Greece
}

\author{
E Petridou, A Skalkidou, I Lescohier, D Trichopoulos
}

Center for Research and Prevention of Injuries Among the Young (CEREPRI), Department of Hygiene and Epidemiology, Athens University Medical School, Athens, Greece and Department of Epidemiology, Harvard School of Public Health, Boston, Massachusetts, USA E Petridou

D Trichopoulos

Center for Research and Prevention of Injuries Among the Young (CEREPRI), Department of Hygiene and Epidemiology, Athens University Medical School, Athens, Greece A Skalkidou

Harvard Injury Control Center,

Boston,

Massachusetts, USA

I Lescohier

Correspondence to: Dr Eleni Petridou,

Department of Hygiene and Epidemiology, Athens University Medical School, 75 M Asias Street, 11527 Athens, Greece.

Accepted 22 December 1997

\begin{abstract}
The protective effect of child restraint and the relative safety of front and rear seating in a population where children often travel unrestrained was assessed in a population based case-control study. The cases were all 129 children aged $0-11$ years injured as car passengers in a motor vehicle accident who contacted, during 1996, one of the two major children's hospitals in Athens; emergency cases are accepted by the two hospitals on alternate days throughout the year, thus generating a random sample of children injured as car passengers. The prevalence of the studied exposures in the study base was estimated from an inspection survey comprising a random sample of 191 children of the same age who travelled in passenger cars. The survey was conducted by medical staff from our centre in collaboration with the road traffic police. Odds ratios (ORs) were calculated after adjustment for confounding factors through the Mantel-Haenszel procedure. The OR for injury was 3.3 among unrestrained children compared with restrained children (comparison essentially limited to children aged $0-4$ years) and 5.0 for children seated in the front compared with those seated in the rear (comparison essentially limited among unrestrained children). Protective effect estimates derived from this analytical study suggest that in Greece about two thirds of all childhood injuries from car crashes could have been avoided through the regular use of a proper child restraint. The data also indicate that, in the absence of a child restraint system, a rear seating position conveys substantial protection and could explain the low mortality of children as car passengers in Greece, a country which is characterised by a high overall road traffic mortality as well as a high childhood accident mortality.

(Arch Dis Child 1998;78:335-339)
\end{abstract}

Keywords: child car restraints; seating positions; protective effects; road traffic injuries

Child safety during transportation by car depends in principle on the same factors that affect adult safety, namely, the skills and the behaviour of the driver and vehicle characteristics as well as the seating position and proper use of restraint systems. Child restraints operate in the same way as adult seat belts, but rear facing restraints have been reported to provide better protection because of the larger head mass and poor head control of infants..$^{1-5}$ The types of child restraint depend on the age and body size of the child: for a body weight up to $10 \mathrm{~kg}$, corresponding to an infant of about 8-12 months, an infant carrier or baby seat is used; a toddler seat is used for body weights up to $18 \mathrm{~kg}$, corresponding to a child of about 4 years of age; and a booster seat or cushion can be used for older children up to body weights of $36 \mathrm{~kg}$ or a height of $150 \mathrm{~cm}$, corresponding to a child of about 11 years of age.

There is evidence relating mostly to adults, but also children, that car restraints convey substantial protection. This is more evident among front seat occupants, whereas rear seating is more advantageous than front seating, particularly among unrestrained occupants..$^{6-10}$ The evidence, however, is not conclusive because it has been undertaken while technical changes were being introduced and varying policies and regulations were being implemented. ${ }^{11}{ }^{12}$ Rear seating of children aged 12 years and under is increasingly recommended because of the presumed higher safety of this seating position and because airbags cannot avoid the small, but apparently genuine, risk imparted by their forceful deployment on a front seated child. ${ }^{13-17}$ An influential school, however, has advocated front seating of properly restrained infants so that the driver can supervise the child during travelling without overt distraction; this practice has been especially favoured in Sweden. ${ }^{2} 1718$

Guidelines for car travel by children have been formulated on the basis of theoretical considerations, results from studies in adults, and limited empirical evidence from studies in children. The evidence for children has been reviewed by Towner et al. ${ }^{19}$ Although generally compatible with theoretical predictions, this evidence is mostly ecological, based on comparisons of childhood injury rates in passenger car crashes before and after the introduction of relevant legislative measures, the issuing of recommendations, or the launching of educational campaigns. In contrast, there are few analytical epidemiological studies assessing the protective effect of rear seating alone in preventing childhood road traffic injuries. In addition, all of these epidemiological studies are based on the matched pair design, in which the risk of serious injury or death of a passenger is compared with that of the driver. This design is both valid and efficient for studies among adults, but it is suboptimal for children because age cannot be adequately controlled in the analysis (drivers are generally adults).

Childhood road traffic mortality among car passengers is low in Greece (table 1), even 
Table 1 Childhood mortality (per 10 ) among car passengers by age group (0-5, 6-9, and 0-9 years) in the European Union member states and the USA about 1993

\begin{tabular}{|c|c|c|c|c|c|c|c|c|c|c|c|c|c|c|c|}
\hline $\begin{array}{l}\text { Age group } \\
\text { (years) }\end{array}$ & Netherlands & Denmark & Finland & Greece & Sweden & Ireland & Spain & Italy & France & $U K$ & Germany & Portugal & Austria & Belgium & $U S A$ \\
\hline $0-5$ & 64 & 211 & 234 & 293 & 344 & 467 & 516 & 515 & 657 & 964 & 1106 & 1029 & 1162 & 1654 & 3108 \\
\hline $6-9$ & 51 & 267 & 279 & 374 & 520 & 500 & 565 & 636 & 524 & 1270 & 1321 & 1261 & 1416 & 1832 & 3394 \\
\hline $0-9$ & 58 & 231 & 252 & 328 & 408 & 481 & 537 & 565 & 589 & 1083 & 1191 & 1127 & 1264 & 1723 & 3218 \\
\hline
\end{tabular}

Source: Statistics of road traffic accidents in Europe and North America. Geneva: United Nations, 1995.

though this country is generally characterised by a high road traffic injury mortality and a high childhood accident mortality. ${ }^{20}$ Most of the educational efforts in Greece have encouraged the seating of children in the rear, but no formal campaign for the use of child car restraints has so far been undertaken. Indeed, the rate of use of child restraint devices is reported to be among the lowest in the European Union (EU) member states. Thus the crude mean of the proportion of children using restraint systems has been reported to be $35 \%$ in Austria, 63\% in Denmark, $71 \%$ in Finland, $75 \%$ in France, $52 \%$ in Germany, $43 \%$ in Netherlands, $87 \%$ in Sweden, and $79 \%$ in the UK, but only $15 \%$ in Greece. ${ }^{17}$

We have undertaken an analytical epidemiological investigation of the protective effect of childhood transportation safety measures using the Emergency Department Injury Surveillance System (EDISS) database developed by the Center for Research and Prevention of Injuries Among the Young (CEREPRI) in Greece. In EDISS, data are recorded from individuals who sought medical attention at any of a network of hospitals for an injury of any nature. For this study, children who were less than 12 years old and therefore needed a childhood restraint system were enrolled among those who contacted one of the two children's teaching hospitals in Athens for a road traffic injury. These two hospitals are located side by side in the same area and, taken together, cover more than $80 \%$ of all childhood admissions. ${ }^{21}$ The two hospitals accept emergency paediatric cases on alternate days throughout the year so that children admitted to any of the two teaching children's hospitals are an essentially unselected sample of the injured children in the underlying population.

\section{Subjects and methods}

From 1 January to 30 November 1996, 19190 children less than 15 years old with unintentional injuries were registered in the EDISS database from "A Kyriakou” Children's Teaching Hospital in Athens. Of those, 129 children were car passengers less than 12 years old who sought hospital medical attention for an injury of variable severity after a motor vehicle accident. The injury severity score ${ }^{22}$ was up to 4 for 109 children, 5 to 9 for 16 children, and 10 or more for the remaining four children. Eleven of these children had fracture(s) and 12 had a head injury with at least some central nervous system involvement. Four health visitors associated with CERERPI interview every child and his or her guardian who seek medical attention for an injury on the basis of a precoded questionnaire. In addition to sociodemographic variables and injury characteris- tics, information on whether the child was seated in the front or rear seat and whether a child restraint system was used is also recorded for children injured in a road traffic accident as rear passengers.

In 1996 CEREPRI also undertook, in collaboration with the road traffic police department, a random inspection survey on the use of seat belts or child car restraints among occupants of passenger cars in the Athens area. During the survey, which lasted 40 days, teams of one CEREPRI interviewer and a road traffic policeman randomly stopped 1400 passenger cars, excluding taxis, in 10 sites on secondary roads, five sites on main road arteries in Athens, and five sites on highways linking the city with the rest of the country. The policeman stopped the car and explained to the driver that a study was being carried out in collaboration with the University of Athens and that no action would be taken in this instance against non-users of seat belts, even though their use is mandatory in Greece. Subsequently, the policeman withdrew and the interviewer inspected the availability and use of seat belts by the car's occupants aged 12 years or older and the use of child restraint systems by younger children. In addition, information was recorded about basic demographic variables, the date, and the time of the day or night. There was no refusal to cooperate and the short inspection and interview ended with advice about the substantial health benefits imparted by the regular use of car restraints. A total of 191 children less than 12 years old were identified and for each of them gender, age, front or rear seating, and the use of a car restraint system at the time of the inspection was recorded (for children less than 5 years a restraint cot or safety seat; for children 5-11 years a seat belt in combination with booster).

The data were analysed as a case-control investigation considering the unselected sample of injured children as cases and children in the inspection survey of the underlying population as controls. Three variables were evaluated as relevant exposures: the non-use of a child restraint system ( $v$ use), front seating ( $v$ rear seating), and being less than 5 years old ( $v$ being at least 5 years old). The MantelHaenszel procedure allows for the control of the variables that are not focused upon during alternative comparisons. The method evaluates the statistical significance of each association after adjustment for confounding influences on the part of the other variables and generates the odds ratio (OR), which is an estimate of how more frequent the injury under study is when a certain categorical exposure is present rather than absent. Finally, the method provides the $95 \%$ confidence interval (CI), which is a 
Table 2 Distribution of 129 children (0-11 years) who had a road traffic accident and of 191 children who were car passengers in a random inspection survey by seating position (front or rear) and use of child car restraint

\begin{tabular}{|c|c|c|}
\hline & Injured & Non-injured \\
\hline \multicolumn{3}{|l|}{ Age $0-4$ years } \\
\hline Front, unrestrained & 10 & 5 \\
\hline Front, restrained & 0 & 1 \\
\hline Rear, unrestrained & 36 & 39 \\
\hline Rear, restrained & 5 & 16 \\
\hline \multicolumn{3}{|l|}{ Age $5-11$ years } \\
\hline Front, unrestrained & 16 & 2 \\
\hline Front, restrained & 0 & 0 \\
\hline Rear, unrestrained & 62 & 128 \\
\hline Rear, restrained & 0 & 0 \\
\hline \multicolumn{3}{|c|}{$\begin{array}{l}\text { Mantel-Haenszel` injury OR }(95 \% \mathrm{CI}) \text { and two tailed } \\
\text { p value }\end{array}$} \\
\hline Unrestrained $v$ restrained & \multicolumn{2}{|c|}{$3.3(1.0$ to 11.4$)(\mathrm{p}<0.05)$} \\
\hline Front $v$ rear seated & \multicolumn{2}{|c|}{$5.0(2.2$ to 13.4$)(\mathrm{p}<0.00005)$} \\
\hline $\begin{array}{l}\text { Front unrestrained } v \text { rear } \\
\text { restrained }\end{array}$ & \multirow{2}{*}{\multicolumn{2}{|c|}{$\begin{array}{l}6.4(1.2 \text { to } 37.7)(p<0.01) \\
1.6(0.9 \text { to } 2.8)(p=0.11)\end{array}$}} \\
\hline $0-4 v 5-11$ years & & \\
\hline
\end{tabular}

${ }^{\star}$ Controlling for the recorded variables that were not included in each of the contrasts (for example, for age and seating position, in the first contrast, etc).

measure of the plausible chance variation of the respective OR.

On the basis of the proportion of children exposed to each of the two main factors (front seating, non-use of a child restraint system) and the corresponding Mantel-Haenszel derived ORs, it is possible to calculate the population attributable fraction. ${ }^{23}$ This is the proportion of childhood injuries among car passengers of similar age in the study population of Greater Athens which would have been avoided if all the children were seated in the rear of the car or were using an appropriate restraint system (or both).

\section{Results}

Table 2 gives the frequency distribution of 129 injured children from the EDISS database and the 191 non-injured children from the inspection survey by age, seating position, and use of a child restraint system. The data from the inspection survey indicate that in the population of Athens most children are travelling without proper restraint systems. This is particularly true with respect to older children, for whom a booster seat must be used. Even among children less than 5 years old, however, a restraint system is used by less than one third $(17 / 61)$. Of note, however, is that most children $(96 \%)$ are travelling in the rear seat.

Unrestrained children are at significantly higher risk of sustaining a motor vehicle injury than restrained children, the OR being 3.3 (lower panel in table 2). This estimate is based on data for rear seated younger children because none of the older children used an appropriate restraint system that would allow proper comparison. Front seating increases the risk for injury fivefold. This OR mainly reflects the occurrence of injury among unrestrained children because the restrained children were all less than 5 years old and, among them, all but one were seated in the rear. As expected, the $\mathrm{OR}$ is very high when children are both unrestrained and seated in the front (OR 6.4), although this particular contrast is based on very few children in the younger age group.
Finally, after adjustment for seating position and restraint use, younger children appear to be at $60 \%$ higher risk of injury than older children $(p=0.11)$.

Miettinen's formula ${ }^{24}$ allows the calculation of the proportion of road traffic injuries among children that could have been avoided if they were all properly restrained or, alternatively, all of them seated in the rear, under the assumption that the relative effectiveness is uniform across all strata. To that effect, the proportion of exposed (unrestrained or, alternatively, front seated) children among the cases is multiplied by $(\mathrm{OR}-1)$ and divided by the OR. It appears that the proper restraint of all children could reduce the number of those injured by $67 \%$ and that the rear seating of all children could reduce this number by $16 \%$.

\section{Discussion}

This study was designed and implemented as an analytical population based and population controlled epidemiological investigation. This characteristic distinguishes it from valuable previous investigations that were either ecological in nature (before/after group comparisons or group randomisation) or relied on the matched pairs design that does not involve a population based group of non-injured children. ${ }^{569-121425}$ Other strengths of this investigation were the medical rather than police ascertainment of injuries, which assures better data quality, ${ }^{26}$ and the use of a control group that captures the exposure pattern of the actual population at risk. The inspection survey used in this study is likely to provide more valid data than those derived from observation surveys based on random intersection or shopping mall observations. ${ }^{27}$ Finally, the situation in Greece allows an efficient evaluation of the protection afforded by rear seating alone, because in this population unrestrained rear seating is common.

Among the weaknesses of this investigation are power limitations and the inability to address the relative safety of seating position (front $v$ rear) among restrained children because most of the restrained children were seated in the rear. Furthermore, the protection imparted by child restraint systems was evaluated only among children younger than 5 years because none of the older children was restrained.

Comparability of cases with controls is always an issue in case-control studies, but, in this investigation, the cases were a random sample of all cases in the study base and the controls were, by design, a random sample of that study base. Accordingly, there should be no selection bias in the study ${ }^{23}$ unless unobserved changes in traffic patterns have compromised the representative nature of the random inspection survey, which appears unlikely. An argument could also be made for using as control subjects children who were involved in car crashes but were not themselves injured. This type of control series would have some advantages, but it is difficult to assemble because uninjured children who were involved in a car crash are not easily accessible. The almost 
unavoidable losses would have created a strong potential for selection bias. Lastly, the exclusion from the case series of children who died as car passengers may have led to an underestimation of the protective potential of car restraints, but historical data suggest that their number is likely to be minimal (less than five).

The results of the present study provide statistically significant evidence that a lack of restraint system among infants and toddlers increases the risk of injury more than threefold. This translates into a protective effect of child restraints for younger children of almost $70 \%$. This figure is slightly lower than, but not incompatible with, the $93 \%$ protective effect reported from a UK study. ${ }^{28}$ Overall, front seating increases the risk of injury fivefold (protective effect $80 \%$ ), but the relative protection appears to be higher among older (5-11 years) than among younger ( $0-4$ years) children. There is some evidence that back seating and restraint use may have an additive protective effect, but the data do not allow firm conclusions. These findings are generally compatible with those reported by other investigators who have used different study designs and the convergence of results adds to confidence in their validity. ${ }^{236141718}$

As indicated, rear seating conveys substantial protection compared with front seating, at least among unrestrained children. The proportion of road traffic injuries that could have been avoided in the underlying population by the universal rear seating of children is deceptively small $(16 \%)$ because most children in Greece are already transported in the rear seats and the potential benefit has already been harvested. Indeed, road traffic injury mortality among child car passengers is as low in Greece as in Nordic countries, and substantially lower than in the USA (table 1). It seems that when the universal use of child car restraint systems is not achievable, a policy that stresses the transportation of children in the rear can provide a substantial protective effect and outstanding cost efficiency for injury prevention while avoiding the risks associated with airbags, however minimal.

On the negative side, this study indicates that most children in Greece (91\%) are transported in passenger cars without the proper use of car restraints and that a regular use of such restraints could reduce the number of childhood injuries after car crashes by two thirds. Even if we restricted consideration to children less than 5 years old, among whom $72 \%$ did not use a car restraint, and the realistic objective was to reduce this proportion to the $34 \%$ observed in the USA population, ${ }^{27} 26 \%$ of all injuries in this age group could be prevented.

The non-use of child car restraints is more extensive in Greece than in most developed countries, but the problem is universal. Several important studies have evaluated the effectiveness of legislative, regulatory, and other public health measures in increasing compliance with passive safety measures for children in passenger cars. These studies and the effectiveness of alternative approaches have also been reviewed by Towner et al. ${ }^{19}{ }^{29-31}$ Our findings confirm that the universal and proper use of child restraint systems is the ultimate objective, but they also suggest that until this goal is accomplished, children should only be transported in the rear seats. If our findings are supported by the results of additional studies, population policies and individual advice for the car transportation of children should emphasise rear seating as much as the use of restraints.

Special thanks are due to the EDISS data manager Ms S Kiose, the health visitors T Diamantopoulou, E Maragaki, L Mera, and $\mathrm{E}$ Tzemanaki, and the road traffic police officers who participated in this study.

1 Kahane CJ. An evaluation of child passenger safety-the effectiveness and benefits of safety seats. Washington, DC: US Department of Transportation, 1986. Technical report No: HS 806890 NHTSA.

2 Aldman B, Gustafsson H, Nygren A, Tingvall C. Child restraints: a prospective study of children as car passengers in road traffic accidents with respect to restraint effectiveness. In: Tingvall C, ed. Children in cars: some aspects of the safety of children as car passengers in road traffic accithe safety of children as car passengers in road
dents. Acta Paediatr Scand $1987 ; \mathbf{S 3 3 9}$ (II): $1-22$.

3 Gustafsson H, Nygren A, Tingvall C. Children in cars: an epidemiological study of injuries to children as car passengers in road traffic accidents. In: Tingvall $C$, ed. Children in cars: some aspects of the safety of children as car passengers in road traffic accidents. Acta Paediatr Scand 1987;S339(I): $1-25$

4 Lowne R, Gloyns PF, Roy P. Fatal injuries to restrained children aged 0-4 years in Great Britain 1972-86. Paper presented to the 11th International Conference of Experimental Safety; 1987; Washington, DC.

5 Carlsson G, Norin H, Ysander L. Rearward-facing child seats - the safest car restraint for children? Accid Anal Prev 1991;23:175-82.

6 Williams AF, Zador P. Injuries to children in automobiles in relation to seating location and restraint use. Accid Anal Prev 1977;9:69-76.

7 Hulke DF. The rear seat occupant in car crashes. Fournal of the American Association of Automobile Medicine 1987;9:214.

8 Evans L, Frich MC. Seating position in cars and fatality risk. Am f Public Health 1988;78:1456-8.

9 Partyka SC. Lives saved by child restraints from 1982 through 1987. Washington, DC: National Highway Traffic Safety Administration, 1988.

10 National Highway Traffic Safety Administration. Revised estimates of child restraint effectiveness. Washington, DC: US Department of Transportation, 1996.

11 Kelleher-Walsh B, Walsh M, States J, Duffy L. Trauma to children in forward-facing car seats. Warrendale: Society of Automotive Engineers; 1993. SAE technical paper: 933095.

12 Walsh M, Kelleher-Walsh B, McCullough C. A study of motor vehicle accidents involving children. In: 40th Stapp Car Crash Conference Proceedings; 1996. Warrendale: Society of Automotive Engineers. SAE technical paper: 962436 .

13 Turbell T. Safety of children in cars. Paper presented at the traffic safety seminar; 1992; Muscat, Oman 25-29 April 1992. Linkoping: Swedish Road and Traffic Research Institute, 1992.

14 Johnston G, Rivara F, Soderberg R. Children in car crashes. Pediatrics 1994;93:960-5.

15 Huelke D, Compton C. The effects of seat belts on injury severity of front and rear occupants in the same frontal crash. Accid Anal Prev 1995;22:835-8.

16 Weber K. Rear-facing restraint for small child passengers. UMTRI Research Reviews 1995;25:12-17.

17 European Transport Safety Council. Seat belts and child restraints: increasing use and optimizing performance. Brussels: ETSC, 1996.

18 Tingvall C. Injuries to restrained children in cars involved in traffic accidents. In: Tingvall C, ed. Children in cars. Some aspects of the safety of children as car passengers in road aspects of the safety of children as car passengers in road

19 Towner E, Dowswell T, Simpson G, Jarvis S. Health promotion in childhood and young adolescents for the prevention of unintentional injuries. Health promotion effectiveness reviews. London: Health Education Authority, 1996.

20 World Health Organisation. World health statistics annual (1994). Geneva: WHO, 1995

1 Petridou E, Simou E, Skondras K, Pistevos G, Lagos P, Papoutsakis G. Hazards of baby walkers in a European context. Inj Prev 1996;2:118-20.

22 The Johns Hopkins University. Health Services Research and Development Center. Injury severity score "ICDMAP" scoring software installation and reference manual. Baltimore: Johns Hopkins University, 1993.

23 MacMahon B, Trichopoulos D. Epidemiology: principles and methods. 2nd Ed. Boston: Little Brown, 1996.

24 Miettinen OS. Proportion of disease caused or prevented by a given exposure, trait or intervention. Am $\mathcal{F}$ Epidemiol
1974;99:325-32. 
25 Argan P, Castillo D, Winn D. Comparison of motor vehicle Argan $\mathrm{P}$, Castillo D, Winn D. Comparison of motor vehicle occupant injuries in restrained and unrestrain

26 Alexandersson S, Gustafsson H, Nygren A, Tingvall C. Quality of data on injured child car passengers in road traffic accidents. A comparison between injuries reported to the National Central Bureau of Statistics (SCB) and to an insurance company. Acta Paediatr Scand 1987;S339:1-9.

27 National Highway Traffic Safety Administration. National occupant protection use survey: controlled intersection study. Research note. Washington, DC: US Department of Transportation, 1995.
28 Narayan KMV, Ruta D, Beattie T. Seat restraint use, previous driving history and non-fatal injury: quantifying the risks. Arch Dis Child 1997;77:335-8.

29 Agran R, Dunkle D, Winn D. Effects of legislation on motor vehicle injuries to children. Am f Dis Child 1987;141:95964 .

30 Margolis L, Wagenaar A, Liu W. The effects of a mandatory child restraint law on injuries requiring hospitalization. $\mathrm{Am}$ f Dis Child 1988;142:1099-103.

31 Lindqvist KS. Does the use of child safety seats increase as a result of loan schemes? Accid Anal Prev 1993;25:421-9.

\section{Müllerian inhibiting substance}

Müllerian inhibiting substance (MIS), or antimüllerian hormone, is produced by testicular Sertoli cells in fetal (and later) life causing regression of the müllerian duct system. In males with normal testes its serum concentration is high at birth and decreases thereafter. In females it is produced by ovarian granulosa cells at and after puberty. Concentrations in adult men and women are similar.

In children an appreciable serum MIS concentration indicates the presence of testicular tissue. Now researchers in Boston, Chicago, and Tokyo (Mary M Lee and colleagues, New England fournal of Medicine 1997;336:1480-6; see also editorial, Ibid: 1519-21) have shown serum MIS measurement to be useful in the assessment of virilised children with no palpable gonads. They tested 65 children with a variety of diagnoses including cryptorchidism, anorchia, gonadal dysgenesis, and adrenogenital syndrome. Mean (SD) concentrations were 48.2 (42.1) $\mathrm{ng} / \mathrm{ml}$ in 34 children with normal testes, 11.5 (11.8) in 14 with abnormal testes, and $0.7(0.5)$ in 17 with no testes. The test was $92 \%$ sensitive and $98 \%$ specific for predicting the absence of testicular tissue, an improvement on tests using testosterone measurements.

The test may prove useful in assessing boys with undescended testes and children with ambiguous genitalia but it is not yet widely available.

ARCHIVIST 